Editorial

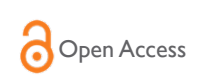

CrossMark

\title{
Medications- information please!
}

\section{Editorial}

“90\% of people wouldn't dream of making a big decision about their car, vacation, or home with so little real time information. The more information you have regarding medications, the more control of the situation you possess." Most people over age 55 take at least one major, and required medication for one serious medical condition - for example high blood pressure, Diabetes, Arthritis or a Cardiac Condition. Most people cannot actually name the medications (especially generic) they are taking, nor understand the specific effect on the condition; for example for high blood pressure-can the medication lower blood pressure to normal, or not; or with diabetes how much of the lowered blood sugar levels is due to the drug taken, how much to diet, and how much to the severity of the condition. What's more, those that are aware that all medications have side-effects don't know which are common and tolerable, and which can actually be life threatening to them.

Most people wouldn't dream of making a big decision about their car, vacation, or home with so little real time information. The essential importance of these medical statistics in this comparison is evident. The question is where, and how and from whom is this critical information to come?

Every M.D., or pharmacist is required to know both the major effect (purpose) as well as the side-effects of every medication dispensed, as well as the ratio of good effect to side-effect in treating their patients. Every medication, even such common ones, often selfprescribed by patients, can potentially cause untoward or unwanted reactions. Consider the analgesic taken by millions for pain relief, the simple Aspirin. It can potentially encourage acid reflux, or serious G.I Bleeding.

Perpetually up for consideration can be- is 'the game worth the candle'.

\section{The physician's responsibility}

Here are a few considerations: No Physician will prescribe a medication that has seriously harmful potential side-effects unless there is no choice in treating a life-threatening condition. By and large if there is a choice of which medication to use for these conditions the Physician will look for the most effective drug with the least number of, and least serious of side effects. And keeping current with the information as it emerges every day in medical journals, reports, and pharmaceutical releases, despite the volume of this material is the Physician's and Pharmacist's responsibility. Now, every prescription medication that may be dispensed to you is accompanied by an
Volume 2 Issue 6 - 2015

\author{
Mary Ellen Hecht \\ Orthopedic Surgeon, USA
}

Correspondence: Mary Ellen Hecht, Orthopedic Surgeon, 240 Central Park S Apt 91, NY 10019 , New York, USA, Tel 2122463474,Email monoarmunna@yahoo.com

Received: June 09, 2015 | Published: June II, 2015

information folder or sheet that describes in comprehensive detail the chemical bases, component make-up, treatment intent, allergic potentials, as well as All potential side effects of the medication. But unfortunately it is printed in what is known as a 'Fly speck' font or print size. That encourages frustrated attempts to read and likely a subsequent discard. However the Pharma who manufactured it, the druggist who sold it, the MD who prescribed it are nevertheless thus enabled to discharge their mandated responsibility to inform the recipient.

\section{The patient's responsibility}

A verbal, layman translation of all medical information is absolutely due the patient. However as a matter of practicality and hours in the day, this is simply not do-able. Also to enlarge print to a reasonable sign and include in the medication's packaging would be virtually encyclopedic and therefore in a word infeasible. However, a small inexpensive hand magnifying glass is easy to obtain and will start to unravel the fly speck information thus supplied. A start, but there remains a problem with this device however adequate for some of us. The pamphlet-supplied information is written in what may be best described as medicalese. That is imbued with technical and scientific terms familiar to the technically and scientifically educatedbut not the general patient population. Moreover TV promotions for new medications, warn of the most dramatic, and threatening side effects their product may induce. But fail to indicate which how common or usual. It is the patient's responsibility to ask the druggist or MD which of these affects they may reasonably expect are relevant to them. And to ensure that the side-effects watch for in taking the medication are made clear. The Patient must ask directly and without fail for this capsulation of relevant information, and then take the time and trouble to write them down for future reference. 